Gut, 1971, 12, 303-310

\title{
Changes in the postoperative insulin test in relation to recurrent duodenal ulceration
}

\author{
D. F. L. WATKIN AND H. L. DUTHIE \\ From the University Department of Surgery, Royal Infirmary, Sheffield
}

SUMMARY The gastric secretory response to insulin changes in many patients between 'immediate' tests, within two weeks of vagotomy, and 'delayed' tests, done at least six months later. Patients who develop recurrent duodenal ulceration after vagotomy and pyloroplasty show highly significant increases in peak and rise in concentration and output of acid. Those who do not have recurrent dyspepsia show varied individual changes in the test results, but for the group as a whole there is no increase in the peak response and only a slight increase in the rise in acid concentration and output.

These findings are interpreted as evidence for vagal recovery, either from neuropraxia or by collateral nerve sprouting, as a major factor in the production of recurrent ulceration. Indeed, it appears to be as important as the functional state of the vagi at the end of the operation. Consequently, only the delayed insulin tests can be of any value in the prediction or diagnosis of recurrence.

The insulin test of gastric secretion may be used in two ways in studying patients after surgical vagotomy, either as a routine test for the completeness of vagal denervation of the stomach or as a diagnostic aid when patients return with further dyspepsia. The latter use depends on the assumption that incomplete vagotomy is the main cause of recurrent ulceration (Bachrach and Bachrach, 1967). This dual role accounts for some of the controversy surrounding the interpretation of the test (Kay, 1967).

Recently, the task of establishing standards for this interpretation has been further complicated by reports of changes in the acid response to insulin with the passage of time after vagotomy (Mason and Giles, 1968 and 1969; Gillespie, Elder, Gillespie, Kay, and Campbell, 1970). Using Hollander's (1948) criteria, as modified by Ross and Kay (1964), the proportions of positive and early positive results in these studies were found to increase with time. The significance of these changes has not been established. We have, therefore, compared the acid response to insulin immediately after vagotomy and several months later, in patients with or without recurrent duodenal ulceration. Significant increases in the acid response have been observed in the later tests in patients with recurrence.

Received for publication 18 January 1971.

\section{Method}

An unselected series of 210 men had had a vagotomy and pyloroplasty performed for duodenal ulcer at least two years previously, followed by an insulin test within two weeks of the operation. Men only were studied, in view of the sex difference in the results of insulin tests (Spencer, Burns, Cheng, Cox, and Welbourn, 1969). One hundred and fifty-five (74.8\%) of these patients attended a followup clinic; seven had died of causes unrelated to duodenal ulcer, 36 declined to attend, and 12 were untraced owing to extensive rehousing in the Sheffield area.

The patients attending for interview were designated as 'recurrence' or 'non-recurrence' solely on the basis of their histories because, in contrast to a recent report (Williams and Toye, 1970), we have found radiological appearances difficult to interpret after pyloroplasty. To avoid bias, the assessment was made independently of the insulin test results. Each patient was graded according to Visick's (1948) classification; a decision was then made as to whether severe symptoms (grades $3 u$ and 4) were due to recurrent duodenal ulceration or to the side effects of the operation. Re-operation did not automatically place a patient in the recurrence 
group. If symptoms were suggestive of gastric ulceration a barium meal examination and a gastroscopy were performed. On this basis, 132 men had no recurrence and 15 had a recurrence; one had a gastric ulcer and seven defied classification.

\section{INSULIN TESTS}

All tests were performed in the Department of Surgery by experienced staff. After an overnight fast, a $5 \mathrm{~mm}$ diameter tube was passed into the stomach and adjusted to give a free return of fasting juice, with the patient recumbent and slightly tilted to his left. Continuous aspiration at a negative pressure of $5 \mathrm{~cm} \mathrm{Hg}$ was applied, with either frequent air insufflation or the use of a second, airvent, tube. After three 15-minute basal collections 0.2 units $/ \mathrm{kg}$ of soluble insulin were given intravenously and a further eight 15-minute samples collected.

The volume of each sample was measured and its acid content titrated to $\mathrm{pH} 8.4$ (the phenolphthalein end point) or to $\mathrm{pH} \mathbf{7 . 0}$ using an Autotitrator (Radiometer). The actual acid values are reported, rather than rating each test as positive or negative with regard to some fixed criterion. 'Basal' figures are the mean of three 15-minute basal readings. 'Peak' acid concentration is the maximum in any 15-minute period after insulin. 'Peak' acid output is taken as the mean of the two highest consecutive 15-minute outputs. The 'rise' in concentration or output is the peak minus the basal value.

\section{TIMING OF INSULIN TESTS}

Tests are described as 'immediate' if done within two weeks of vagotomy and 'delayed' when performed at six months or later. These terms are introduced to avoid confusion with 'early' and 'late' positive responses to insulin (Ross and Kay, 1964).

Sixty of the 132 non-recurrence patients agreed to delayed tests, all of which were done at least two years postoperatively. The median values for the immediate tests in these 60 are not different from those for the other 72 patients (Table I) so that they appear representative of the whole series. Fifty of this group with two tests had had a truncal vagotomy and 10 selective vagotomy.
All 15 patients with recurrence had delayed tests. In seven, these had been carried out at between six months and two years from the primary operation: the remainder were tested at least two years postoperatively. In one immediate test in this group recovery of gastric content after giving insulin was unsatisfactory, so that his concentration and basal output data only could be used. Ten of this group had truncal and five had selective vagotomy.

The paired immediate and delayed tests in 60 non-recurrence and 15 recurrence patients are the subject of comparison in this paper.

\section{STATISTICAL METHODS}

Non-parametric methods have been used because the data were not normal in distribution (eg, Figs. 1 and 3). The Mann-Whitney $U$ test (Mann and Whitney, 1967) has been used for the significance of differences between groups and Wilcoxon's matched pairs signed ranks test (Wilcoxon, 1945) for changes between pairs of tests. Correlations between the immediate and delayed tests were sought by means of Spearman's rank correlation coefficient (Hotelling and Pabst, 1936).

\section{Results}

\section{ACID CONCENTRATION}

Comparison of paired immediate and delayed tests in the non-recurrence group showed a small decrease in the basal concentration with a corresponding increase in the rise after insulin; peak concentration did not change significantly. In the recurrence group a significant increase was found in median peak acid concentration, from 70 to 105 m-equiv/litre $(P<0.01)$ and in the rise in acid concentration from 7 to 72 m-equiv/litre $(P<0.01)$ (Fig. 1). For clarity, these changes in the median values are presented without supporting data in Figure 2.

Comparison of the immediate tests in the nonrecurrence and recurrence groups showed no statistically significant differences, but in the delayed tests the peak and rise in concentration were significantly greater in the recurrence group $(P<0.001)$.

\begin{tabular}{|c|c|c|c|c|c|c|}
\hline \multirow[t]{2}{*}{ Patient } & \multicolumn{3}{|c|}{ Acid Concentration ${ }^{1}$ (mequiv/litre) } & \multicolumn{3}{|c|}{ Acid Output ${ }^{1}$ (m-equiv/15 min) } \\
\hline & Basal & Peak & Rise & Basal & Peak & Rise \\
\hline $\begin{array}{l}60 \text { with paired tests } \\
72 \text { with immediate test only }\end{array}$ & $\begin{array}{l}35 \\
26 \cdot 5\end{array}$ & $\begin{array}{l}49 \cdot 5 \\
36\end{array}$ & $\begin{array}{l}+9 \\
+3.5\end{array}$ & $\begin{array}{l}0.48 \\
0.40\end{array}$ & $\begin{array}{l}0.37 \\
0 \cdot 33\end{array}$ & $\begin{array}{l}+0.01 \\
-0.04\end{array}$ \\
\hline
\end{tabular}

Table I Median values for acid secretion in immediate insulin tests in non-recurrence patients

${ }^{1}$ For each comparison $P>0.05$. 


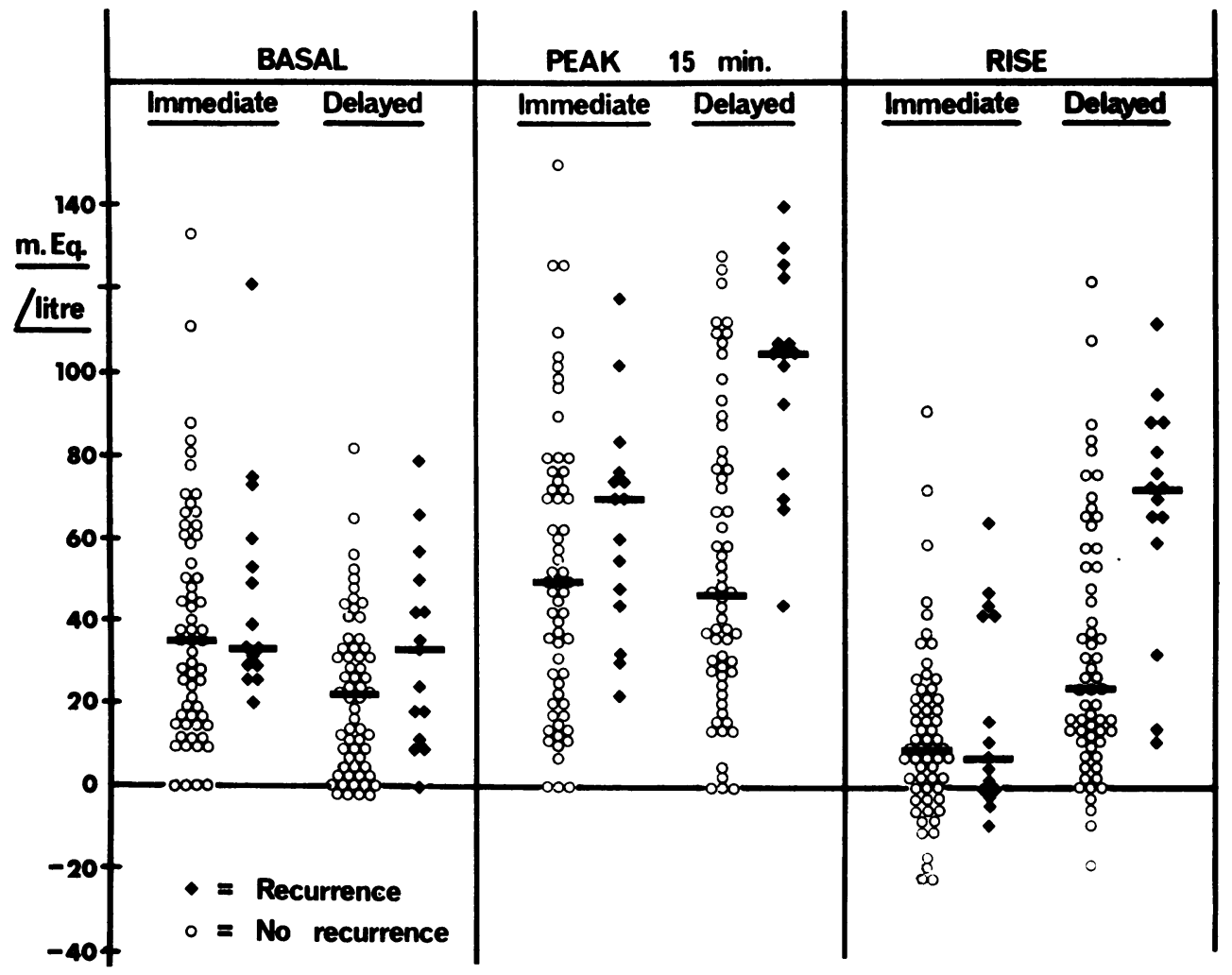

Fig. 1 Acid concentration data in immediate and delayed insulin tests (bars indicate median values).

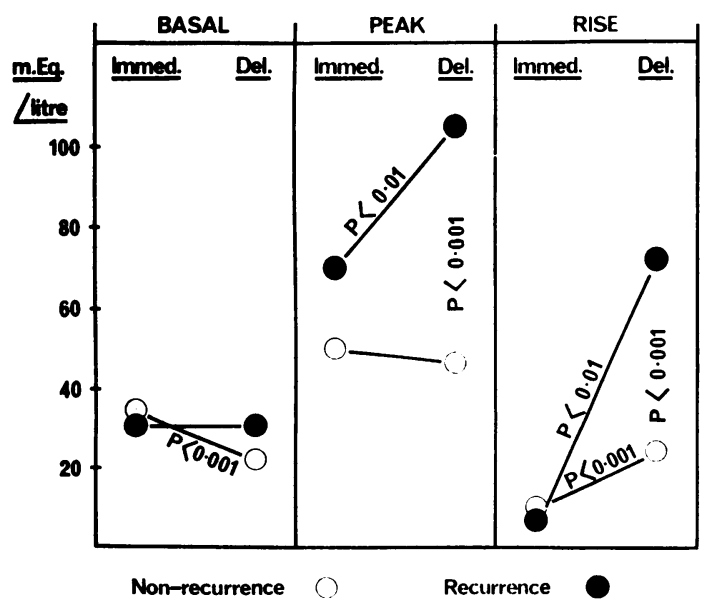

Fig. 2 Median acid concentration values in immediate and delayed insulin tests.
ACID OUTPUT

A pattern similar to the changes in concentration was observed (Fig. 3), there being large and statistically significant increases in peak and rise in output in the recurrence group $(P<0.01$ and $P<0.02$ respectively). There were corresponding highly significant differences between the groups in the delayed tests $(P<0.001)$.

\section{INDIVIDUAL CHANGES}

When changes between the immediate and delayed tests were studied in the individual patients (Figs. 4 and 5) it was found that in the non-recurrence group the changes had an approximately normal distribution centred on zero. The recurrence group showed a predominance of increases in the 'peak' and 'rise' results. The wide scatter of changes indicated that some results moved from one end of the range to the other and that this might occur in 


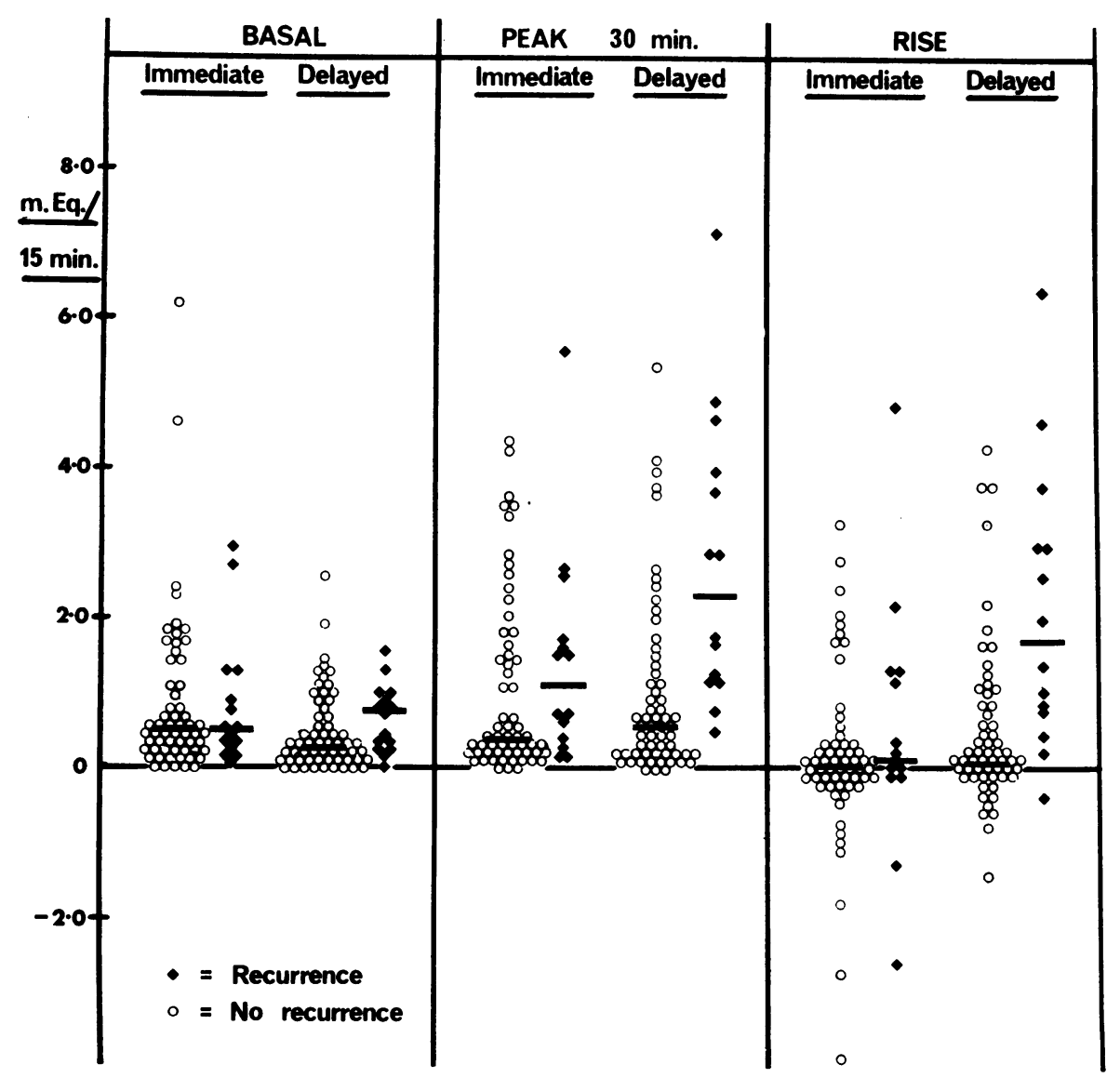

Fig. 3 Acid output data in immediate and delayed insulin tests (bars indicate median values).

either direction. The small number of patients with selective vagotomy showed no separate trend.

When a correlation was sought between the results of the immediate and delayed tests, low values were obtained for the correlation coefficient even though it reached statistically significant levels in some instances (for values for Spearman's rank correlation coefficient and associated probabilities see Table II).
RESPONSE ACCORDING TO THE ESTABLISHED CRITERIA

The effect of these changes on the incidence of positive responses according to various established criteria for interpretation of the insulin test is set out in Table III. The criteria based on acid output have been modified to conform to our 30-minute peak output measurement. By these criteria, between

\begin{tabular}{lll}
\hline & Non-recurrence Group & Recurrence Group \\
\hline Basal acid concentration & $0.247(\mathrm{P}>0.05)$ & 0 \\
Peak acid concentration & $0.342(\mathrm{P}<0.01)$ & $0.313(\mathrm{P}>0.05)$ \\
Rise in acid concentration & $0.410(\mathrm{P}<0.01)$ & $0.567(\mathrm{P}<0.05)$ \\
Basal acid output & $0.222(\mathrm{P}>0.1)$ & $0.300(\mathrm{P}>0.05)$ \\
Peak acid output & $0.412(\mathrm{P}<0.01)$ & $0.612(\mathrm{P}<0.05)$ \\
Rise in acid output & $0.254(\mathrm{P}>0.05)$ & $0.503(\mathrm{P}<0.05)$ \\
\hline
\end{tabular}

Table II Spearman's rank correlation coefficient for immediate and delayed insulin tests 

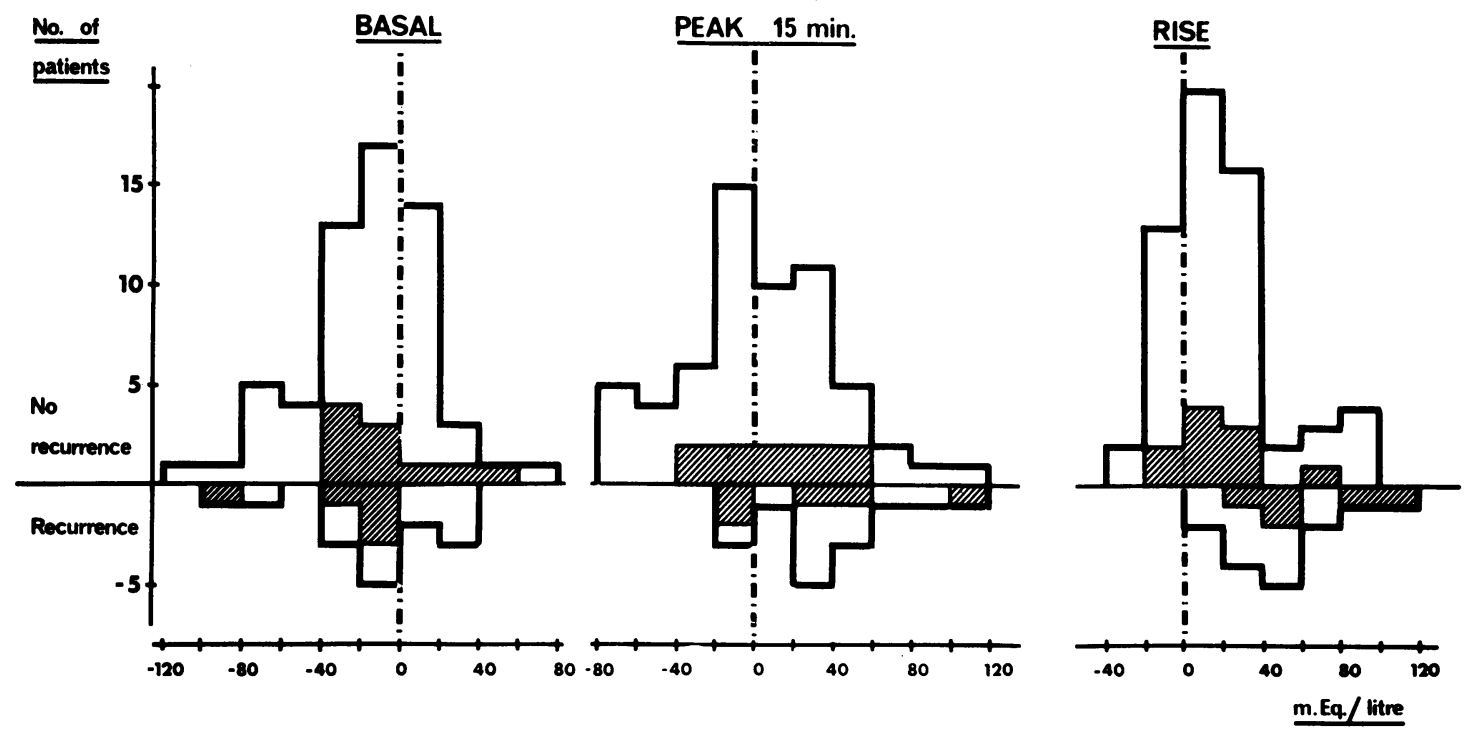

Fig. 4 Frequency distribution of changes in acid concentration between immediate and delayed insulin tests. The crosshatched areas represent selective vagotomies.
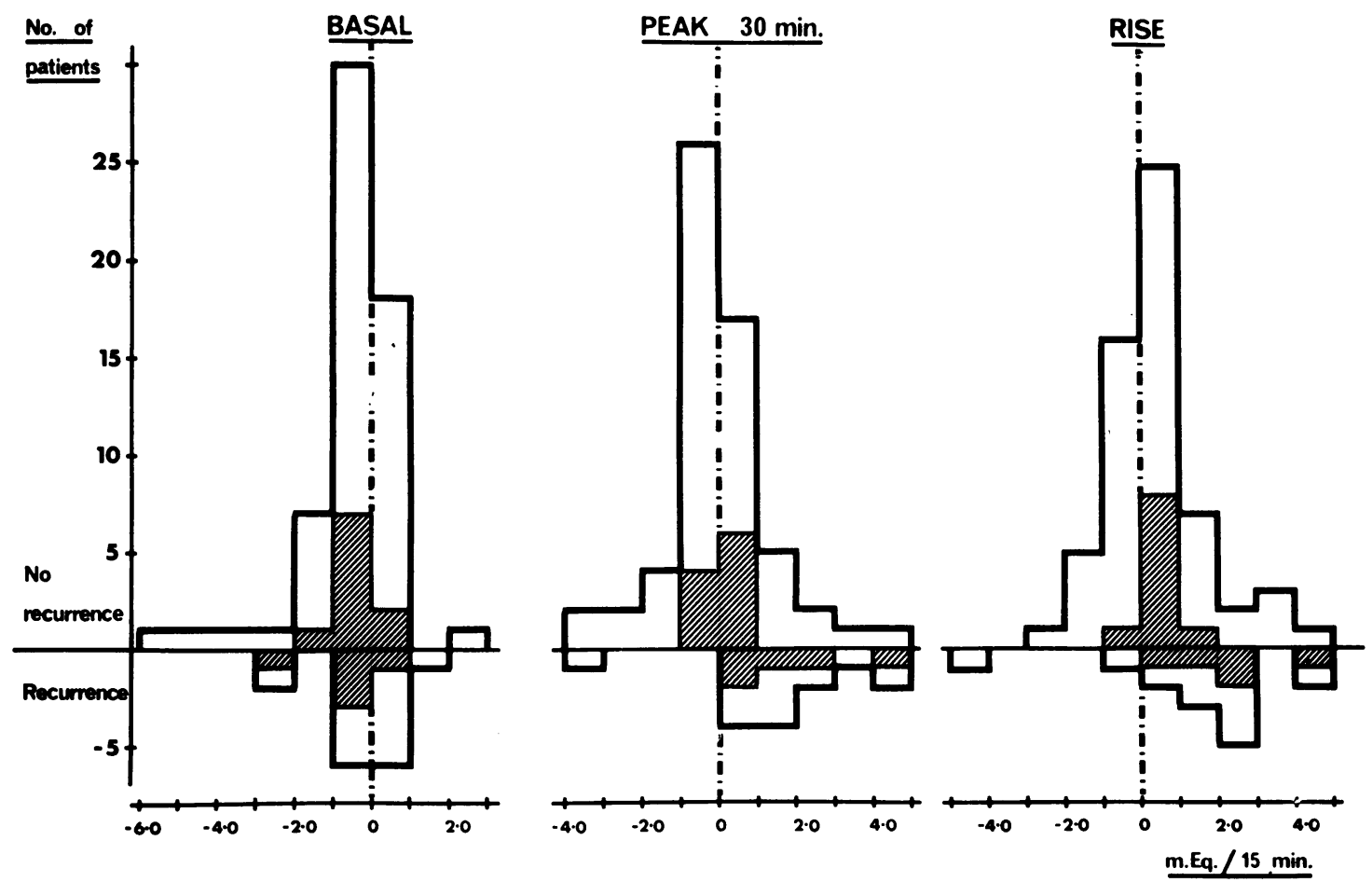

Fig. 5 Frequency distribution of changes in acid output between immediate and delayed insulin tests. The crosshatched areas represent selective vagotomies. 


\begin{tabular}{|c|c|c|c|c|c|}
\hline \multirow[t]{2}{*}{ Criteria for a Positive Result } & \multirow[t]{2}{*}{ No. of Patients } & \multirow{2}{*}{$\begin{array}{l}\text { No. Positive by } \\
\text { Immediate Test }\end{array}$} & \multirow{2}{*}{$\begin{array}{l}\text { No. Positive by } \\
\text { Delayed Test }\end{array}$} & \multicolumn{2}{|l|}{ Change } \\
\hline & & & & $\begin{array}{l}\text { Negative to } \\
\text { Positive }\end{array}$ & $\begin{array}{l}\text { Positive to } \\
\text { Negative }\end{array}$ \\
\hline 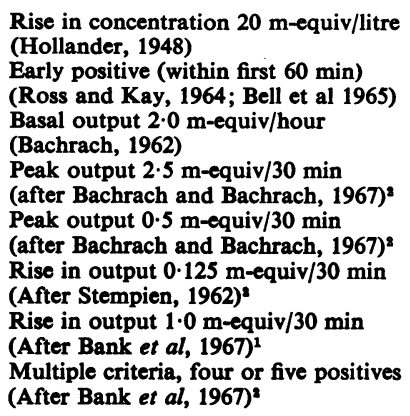 & $\begin{array}{l}60 \mathrm{NR}^{1} \\
15 \mathrm{R} \\
60 \mathrm{NR} \\
15 \mathrm{R} \\
60 \mathrm{NR} \\
15 \mathrm{R} \\
60 \mathrm{NR} \\
14 \mathrm{R} \\
60 \mathrm{NR} \\
14 \mathrm{R} \\
60 \mathrm{NR} \\
14 \mathrm{R} \\
60 \mathrm{NR} \\
14 \mathrm{R} \\
60 \mathrm{NR} \\
14 \mathrm{R}\end{array}$ & $\begin{array}{r}15 \\
5 \\
6 \\
1 \\
29 \\
8 \\
20 \\
7 \\
43 \\
12 \\
25 \\
5 \\
13 \\
5 \\
8 \\
2\end{array}$ & $\begin{array}{r}32 \\
13 \\
15 \\
9 \\
19 \\
8 \\
16 \\
9 \\
40 \\
14 \\
36 \\
13 \\
21 \\
11 \\
15 \\
8\end{array}$ & $\begin{array}{r}20 \\
8 \\
11 \\
8 \\
9 \\
2 \\
9 \\
2 \\
9 \\
2 \\
18 \\
8 \\
13 \\
7 \\
9 \\
6\end{array}$ & $\begin{array}{r}3 \\
0 \\
2 \\
0 \\
19 \\
2 \\
13 \\
0 \\
12 \\
0 \\
7 \\
0 \\
5 \\
1 \\
2 \\
0\end{array}$ \\
\hline $\begin{array}{l}\text { Mean for the eight criteria } \\
\text { Mean for the eight criteria }\end{array}$ & $\begin{array}{l}60 \mathrm{NR} \\
14 \text { or } 15 R\end{array}$ & & & $\begin{array}{l}12 \cdot 3 \\
(20.5 \%) \\
5 \cdot 4 \\
(37 \cdot 4 \%)\end{array}$ & $\begin{array}{l}7.9 \\
(13 \%) \\
0.4 \\
(2 \cdot 6 \%)\end{array}$ \\
\hline
\end{tabular}

Table III Results of insulin tests according to various established criteria

${ }^{1} \mathrm{NR}=$ non recurrence, $\mathbf{R}=$ Recurrence

'The output criteria quoted have been reduced from the one or two hour periods specified by their authors to a proportionate value for the peak $30 \mathrm{~min}$ period used in this study.

a fifth and a half of the patients changed status between immediate and delayed tests.

In the non-recurrence group the average change for these eight criteria was from negative to positive in $20.5 \%$ of patients and from positive to negative in $13 \%$. The change in the recurrence group was nearly always from negative to positive, there being only three exceptions. Overall, there was a net change from negative to positive in $7.6 \%$ of instances in the non-recurrence group and in $35 \%$ of the recurrent ulcer group.

\section{Discussion}

These changes in the gastric secretory response to insulin over the first six months to two years after vagotomy are in general agreement with those previously reported. We have employed the actual acid values in making this comparison, while others have compared the proportions of patients positive on Hollander's (1948) criteria. Mason and Giles (1968 and 1969) found that of 36 patients who had given negative results within 10 days of vagotomy, 17 gave positive results at six months or later, while of 26 patients with positive tests initially, all but two remained so. Similarly, Gillespie et al (1970) had 17 of 31 patients change from negative to positive, but only four of 43 positive patients became negative on retesting three months to four years postoperatively. In the present combined series of 75 non-recurrence and recurrence patients,
28 changed from negative to positive, while three went in the reverse direction. None of these series is made up of consecutive vagotomies, so they are not directly comparable, nor do they indicate the true incidence of changes in the insulin response; this must await a prospective study. Nevertheless, they all show a net increase in the proportion of positive responses (Hollander, 1948) in the months following vagotomy. A similar effect is seen when other criteria for interpretation of the test are applied to the data from the present series (Table III).

The new feature demonstrated is the marked increase in acid concentration and output in the delayed tests in the recurrent ulcer group, while the non-recurrence patients, as a group, show little change over the immediate test. This finding has implications for the pathogenesis of recurrent ulceration and for the timing and significance of insulin tests.

\section{MECHANISM OF THE CHANGES}

These changes in the acid response to insulin in the recurrent ulcer group might, theoretically, be due to increased responsiveness of the parietal cells, recovery from a transient nerve lesion (neuropraxia), or re-innervation. The latter might occur by regeneration at the site of vagal section or by collateral nerve sprouting from a small number of intact fibres (Murray, 1962). The stability of the response to histamine from 10 days to three years postoperatively (Bell, 1964) and the tendency for pentagastrin- 
stimulated secretion to diminish over a like period (Johnston, Lari, and Jepson, 1970) appear to rule out any increase in end organ sensitivity. Regeneration of nerve fibres to bridge the gap is unlikely to be the mechanism in view of the usual finding, at re-operation, of a virgin vagal strand (Fawcett, Johnston, and Duthie, 1969).

Direct evidence is lacking regarding the other possibilities. In particular, that concerning collateral sprouting is far removed from human gastric secretion. The evidence in its favour was obtained from gastric motility studies in cats (Clark, 1964) while that against was based on measurement of the area of mucosa capable of secreting phenol red in the dog (Legros and Griffith, 1970) and the rat (Jones and Griffith, 1970a), supported by secretory measurements (using the pyloric ligation technique) in a separate group of rats (Jones and Griffith, 1970b). We, therefore, cannot at present exclude the possibility of collateral sprouting in man.

We have no anatomical information concerning the state of the vagi in our patients and can only speculate about the mechanism of the changes. Any theory must accord with their observed characteristics of unpredictability, delayed onset, and gradual progression over several months. The time course is unduly prolonged for simple neuropraxia to be the sole explanation. Collateral sprouting appears more likely to have the above characteristics, but its extent is put in doubt by the animal evidence.

\section{THE TIMING AND SIGNIFICANCE OF}

\section{INSULIN TESTS}

The practical value of the insulin test after vagotomy for duodenal ulcer lies in the correlation between the results and recurrence. This is the basis for its use, whether as a routine check on operative technique or as part of the investigation of recurrent symptoms.

The present study confirms the expectation that a correlation exists between delayed insulin tests and recurrence. Immediate tests, done within two weeks of operation, give no indication as to which patients are at risk. The delayed tests described here were carried out at least six months and, generally, two years after vagotomy. The minimum interval after which the 'final' state of vagal innervation of the stomach has been attained remains to be established by serial tests at intervals of a few months. The longer this interval proves to be, the less feasible will routine testing become. Meanwhile, pending a definite figure for this minimum interval, decisions concerning the diagnosis or surgical treatment of recurrence should take account only of tests done after the onset of symptoms.

Previous favourable reports of discrimination between recurrence and non-recurrence (Johnston, Thomas, Checketts, and Duthie, 1967) exploited the increases in the response to insulin which occur in the postoperative months. They were generally comparing immediate tests in the non-recurrence patients with delayed tests in patients with recurrent ulceration. The wide scatter of individual results in Figs. 1 and 3 shows that when the delayed test is used for both groups, there is considerable overlap between them. Thus, even the delayed insulin test does not differentiate fully between those liable or not liable to recurrent duodenal ulceration after vagotomy. The degree of discrimination obtainable is assessed, using larger groups of patients, in a subsequent paper (Watkin and Duthie, 1970).

References

Bachrach, W. H. (1962). Laboratory criteria for the completeness of vagotomy. Amer. J. dig. Dis., 7, 1071-1085.

Bachrach, W. H., and Bachrach, L. B. (1967). Re-evaluation of the Hollander test. Ann. N.Y. Acad. Sci., 140, 915-923.

Bank, S., Marks, I. N., and Louw, J. H. (1967). Histamine-and insulin-stimulated secretion after selective and truncal vagotomy. Gut, 8, 36-41.

Bell, P. R. F. (1964). The long term effect of vagotomy on the maximal acid response to histamine in man. Gastroenterology, 46, 387-391.

Bell, P. R. F., Checketts, R. G. Johnston, D., and Duthie, H. L. (1965) 'Augmented histamine response after incomplete vagotomy. Lancet, 2, 978-979.

Clark, C. G. (1964). Recovery of gastric function after incomplete vagotomy. Brit. J. Surg., 51, 539-542.

Fawcett, A. N., Johnston, D., and Duthie, H. L. (1969). Revagotomy for recurrent ulcer after vagotomy and drainage for duodenal ulcer. Brit. J. Surg., 56, 111-116.

Gillespie, G., Elder, J. B., Gillespie, I. E., Kay, A. W., and Campbell, E. H. G. (1970). The long term stability of the insulin test. Gastroenterology, 58, 625-632.

Hollander, F. (1948). Laboratory procedures in the study of vagotomy (with particular reference to the insulin test). Gastroenterology, 11, 419-425.

Hotelling, H., and Pabst, M. R. (1936). Rank correlation and tests of significance involving no assumption of normality. Ann. Math. Statist., 7, 29-43.

Johnston, D., Lari, J., and Jepson, K. (1971). The pentagastrin response after vagotomy. In press.

Johnston, D., Thomas, D. G., Checketts, R. G., and Duthie, H. L. (1967). An assessment of post-operative testing for completeness of vagotomy. Brit. J. Surg., 54, 831-833.

Jones, W. M., and Griffith, C. A. (1970a). On the question of vagal re-innervation of the stomach, Part I. The permanence of the amount of residually innervated gastric mucosa. Ann. Surg., 171, 365-368.

Jones, W. M., and Griffith, C. A. (1970b). On the question of vagal re-innervation of the Stomach Part II The unchanging secretory and ulcerogenic potential. Ann. Surg., 171, 369-372.

Kay, A. W. (1967). An evaluation of gastric acid secretion tests. Gastroenterology, 53, 834-844.

Legros, G., and Griffith, C. A. (1970). The permanence of adequate incomplete vagotomy; a preliminary study in dogs. Surgery, 67, 654-657.

Mann, H. B., and Whitney, D. R. (1947). On a test of whether one of two random variables is stochastically larger than the other. Ann. Math. Statist., 18, 50-60.

Mason, M. C., and Giles, G. R. (1968). The postoperative insulin test: failure to detect incomplete vagotomy in patients with high acid levels. Brit. J. Surg., 55, 865.

Mason, M. C., and Giles, G. R. (1969). The post-operative insulin test: a further assessment. Brit. J. Surg., 56, 384. 
Murray, J. G. (1962). Sprouting of nerves: some consequences of vagotomy and sympathectomy. Gastroenterology, 42, 197-200.

Ross, B., and Kay, A. W. (1964). The insulin test after vagotomy. Gastroenterology, 46, 379-386.

Spencer, J., Burns, G. P.. Cheng, F. C. Y., Cox, A. G., and Welbourn, R. B. (1969). Difference between males and females in the Hollander insulin test. Gut, 10, 307-310.

Stempien, S. J. (1962). Insulin gastric analysis: technic and interpretations. Amer. J. dig. Dis., 7, 138-152.
Visick, A. H. (1948). A study of the failures after gastrectomy. Ann. roy. Coll. Surg. Engl., 3, 266-284.

Watkin, D. F. L. (1970). The delayed insulin test and recurrent duodenal ulceration. Brit. J. Surg. In press.

Wilcoxon, F. (1945). Individual comparisons by ranking methods. Biometrics Bull., 1, 80-83.

Williams, J. A., and Toye, D. K. M. (1970). Recurrent ulcer after vagotomy and pyloroplasty: the $x$-ray appearances and their value in diagnosis. Gut, 11, 405-408.

\section{The March 1971 Issue}

\section{THE MARCH 1971 ISSUE CONTAINS THE FOLLOWING PAPERS}

Protein loss and cell loss from the small-intestinal mucosa L. R. DA CosTA, D. N. CROFT, AND B. CREAMER

Absorption of glucose, sodium, and water by the human jejunum studied by intestinal perfusion with a proximal occluding balloon and at variable flow rates R. MODIGLIANI AND J. J. BERNIER

Behaviour of the rectal juvenile polyp in vitro HANS RÖMER, CARLOS COTTE, AND ERVIN ESSENFELD-YAHR

Gastric acid secretion in sickle-cell anaemia LADE WOSORNU AND F. I. D. KONOTEY-AHULU

Mucosubstances in neoplasms of the human colon and rectum S. G. SUBBUSWAMY
The prognosis and risk of missing malignant disease in patients with unexplained and functional diarrhoea C. F. HAWKINS AND R. COCKEL

Major hepatic resections in infancy and childhood J. M. HOWAT

A cross-over comparison of the effect of morphine, pethidine, pentazocine, and phenazocine on biliary pressure G. ECONOMOU AND J. N. WARD-MCQUAID

Progress report Alcohol and the liver PETER W. BRUNT

Progress report Gastrointestinal structure and function in germ-free or gnotobiotic animals G. R. THOMPSON AND P. C. TREXLER

Notes and activities

Copies are still available and may be obtained from the PUBLISHING MANAGER,

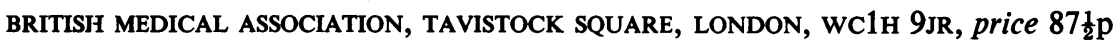

